\title{
Evidence of bhellar (Trewia nudiflora) seed dispersal by chital (Axis axis) in Chitwan National Park, Nepal
}

\author{
Bed Bahadur Khadka' ${ }^{1}$ | Babu Ram Lamichhane ${ }^{2 *}$ (D) \\ ${ }^{1}$ Chitwan National Park Office, Kasara, Chitwan, Nepal \\ ${ }^{2}$ National Trust for Nature Conservation, Biodiversity Conservation Center, Sauraha, Chtiwan, Nepal \\ * Correspondence: baburaml@gmail.com
}

Received: 09 August 2019 | Revised: 07 June 2020 | Accepted: 08 June 2020

\begin{abstract}
In riverine forest of Chitwan National Park, Nepal, Bhellar or trewia (Trewia nudiflora) is one of the most abundant tree species. Similarly, chital (Axis axis) is the most abundant and widely distributed deer species. We documented the potential role of chital in seed dispersal of trewia tree in Chitwan. We observed the trewia seeds regurgitated by chital at the Gharial Conservation and Breeding Center (GCBC), Kasara, Chitwan. The trewia seeds were recorded the following morning of the chital sheltering the GCBC. A detailed study is suggested to understand trewia the seed germination success and trewia-chital relationship.
\end{abstract}

Keywords: Bhellar Trewia nudiflora, Chital, Plant-herbivore interaction, Riverine forest, Seed dispersal

\section{1 | Introduction}

Animals, particularly herbivores play an important role in dynamics of natural vegetation (Corlett 1998). They consume plant parts for survival which can limit the growth of preferred plants. Animals, especially arboreal frugivores such as primates, birds, and bats, also positively affect the plants they eat through seed dispersal (Dubost 1984, Dinerstein 1989). However, only few studies have examined seed dispersal by terrestrial herbivores like ruminants. Ruminants swallow whole fruits while foraging and chew the cud while resting. After chewing, small seeds $(<5 \mathrm{~mm})$ pass through their digestive canal and remain in a viable state in their dung (Bodmer 1991, Middleton \& Mason 1992). In contrast, large ( $>5 \mathrm{~mm}$ ) seeds cannot pass through omasum to abomasum and are regurgitated out by the ruminants (Prasad et al. 2006). Herbivores play important role in structuring the forest structure through such seed dispersal and increasing germination success of many plant species (Dubost 1984 Dinerstein \& Wemmer 1988, Cosyns et al. 2005).

In the sub-tropical riverine habitats of Chitwan National Park (CNP), Nepal, trewia (Trewia nudiflora) is one of the most successful tree species and its success largely depends on seed dispersal by herbivores (Dinnerstein \& Wemmer 1988). There are various studies documenting the association of the greater onehorned rhino (Rhinoceros unicornis) and the trewia (Dinerstein \& Wemmer 1988, Dinerstein 1989, Dinerstein 1991, Baral 2001). The trewia is a deciduous flowering tree (dioecious with 0.72 male: female ratio; Dinnerstein \& Wemmer 1988). The trees flower during March-April and fruits ripe during the monsoon; starting early monsoon (June) and peaks in the mid-late monsoon (July-August). Ripe fruits undergo a slight color change and fall to the ground. By the late August, in the parts of high density trewia trees, fruit carpets the floor of the riverine forests. The ripe fruits of trewia are not favored by various frugivorous fauna such as bats, birds, and monkeys but rhinoceroses consume in the large quantities ( 197 fruits or wet mass of $5.1 \mathrm{~kg}$ per day) during monsoon and post-monsoon period with a peak in September (Dinerstein \& Wemmer 1988).

Previous studies demonstrated rhinoceroses as the primary driver of trewia seed dispersal but role of other highly abundant herbivores such as chital has been ignored (Mishra 1982). Chital (Axis axis) is the medium sized deer species (shoulder height 
male: $90 \mathrm{~cm}$, female: $75 \mathrm{~cm}$; weight male: $71 \mathrm{~kg}$, female: $50 \mathrm{~kg}$ ) indigenous to the Indian sub-continent (Mishra 1982). It is the most abundant ungulate in the CNP (density 44 animals per $\mathrm{km}^{2}$ in 2013) and major prey species of the tiger (Panthera tigris) and leopard (P. pardus) (Dhakal et al. 2014, Lamichhane et al. 2019). This study reports the feeding and seed dispersal of trewia by chitals. Highly abundant and widely distributed herbivores like chital possibly have a greater role in seed dispersal of trewia.

\section{2 | Methods}

This observation was carried out primarily at the Gharial Conservation and Breeding Center (GCBC) (273'11.9" N, 84²0'20.33" E) in CNP, close to the park headquarter, Kasara. The park lies in south central Nepal (Fig. 1). The CNP, a World Heritage Site, is well known for its rich biodiversity including the rhinoceroses, tigers, elephants, gharial (Gavialis gangeticus) and many other rare and endangered wildlife. It has monsoonal subtropical climate with three distinct seasons i.e. monsoon (June September), winter (October- February) and summer (March -
May) (Subedi et al. 2013). Majority of the park ( 70\%) is covered by sal (Shorea robusta) forest. Floodplain grasslands (9.6\%) and riverine forests in different stages of succession with majority of trewia, bombax (Bombax ceiba), khair (Acacia catechu) and sisso (Dalbergia sissoo) cover relatively the smaller area (10\%) but support a high density of wildlife (Lamichhane et al. 2019).

The GCBC was established in 1978 to initiate captive breeding of the gharial crocodiles. It is situated at the elevated land (about $10 \mathrm{~m}$ above the river floodplain) covering about two hectors of area. The GCBC lies at the edge of riverine forest (dominated by trewia) and sal forest. However, there are no trewia trees within the GCBC premises. A large herd of chital frequently shelter in the open space of the GCBC in night, especially during the rainy seasons when grasslands are covered with tall grass and the bushes are dense in the forest. They probably come nearby the shelter to avoid the predator and also looking for safe place from flood. As there is very limited space for grazing at the GCBC, they generally rest and regurgitate and chew their cud while resting at its periphery.

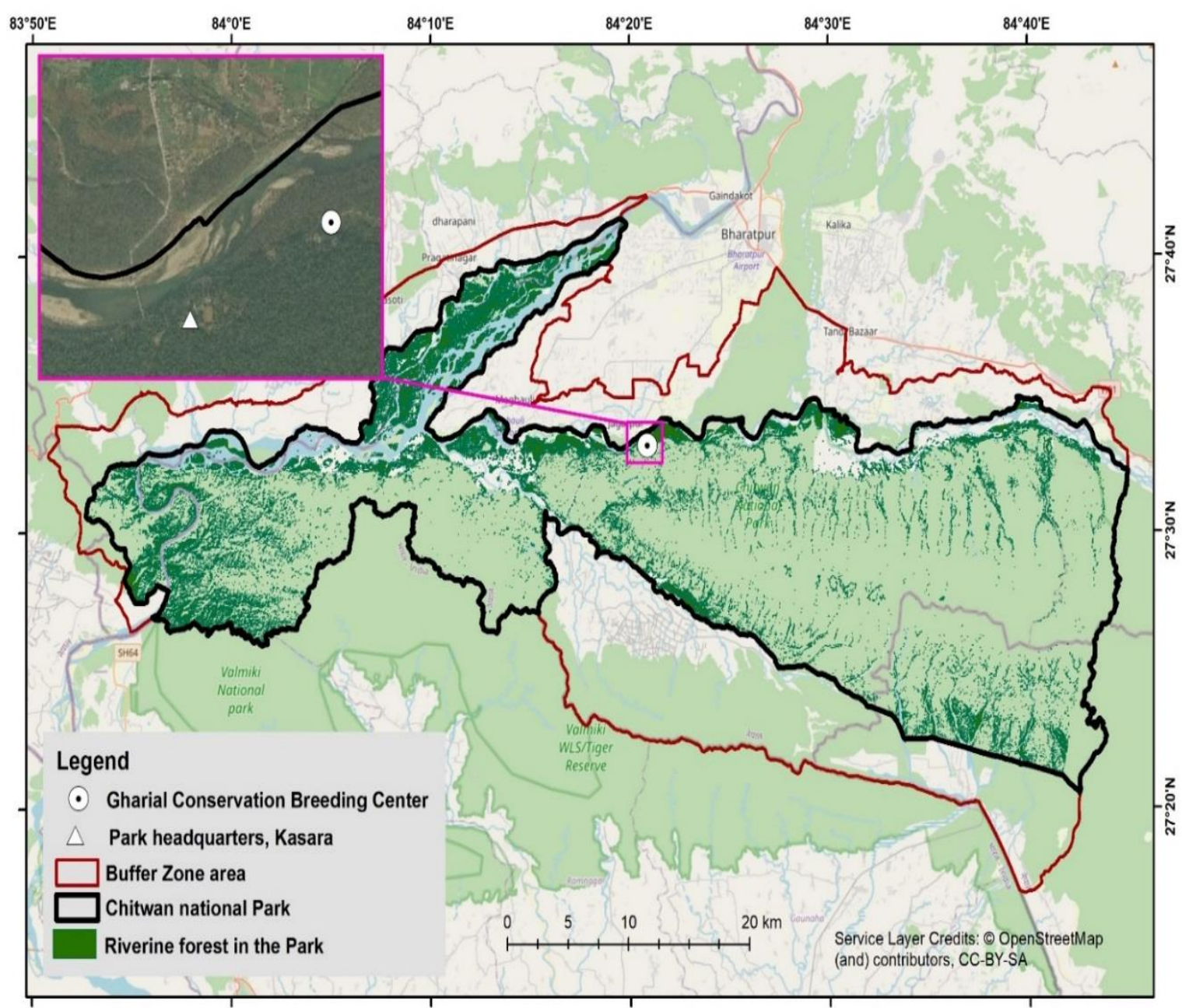

Figure 1. Map of Chitwan National Park showing study location (Gharial Conservation Breeding Center). 
Following morning of the Chital shelter at the GCBC, first author searched for the groups of the trewia seeds and counted. The number of seed groups and number of seeds in each group were recorded in a data sheet. Seeds close to each other $(<30 \mathrm{~cm}$ distance) were counted as a group. The floor of the GCBC was cleaned every morning that minimized the probability of repeated count of the same group of seeds next morning. Observation was made in rainy (monsoon) season of two years i.e. 2016 and 2017 Similarly, we collected 100 trewia fruits randomly from the forest patch of about one hector next to the GCBC. We picked the handful of fresh fruits from the forest floor in one point, moved $\sim 10 \mathrm{~m}$ and picked another handful till we have enough (i.e. 100 fruits). The fruits were crushed and seeds were taken out carefully. The number of seeds in each fruit was counted. The average number of seeds per fruit was calculated and it was used to reconstruct the average fruits consumed by the chitals per night at our observation site (GCBC).

\section{3 | Results}

\section{1 | Regurgitated trewia seeds}

We counted a daily average of 77 and 97 trewia seeds in 5.9 and 6.8 groups in the monsoon season of 2016 and 2017 respectively (Table 1). The trewia trees are not present at GCBC and the seeds will not come out while dropping from the trees. Thus, the chitals must have carried and dropped the trewia seeds at GCBC. Observation at the GCBC (partially chewed parts associated with the seed groups) shows that chitals regurgitate the seeds out while chewing the cud.

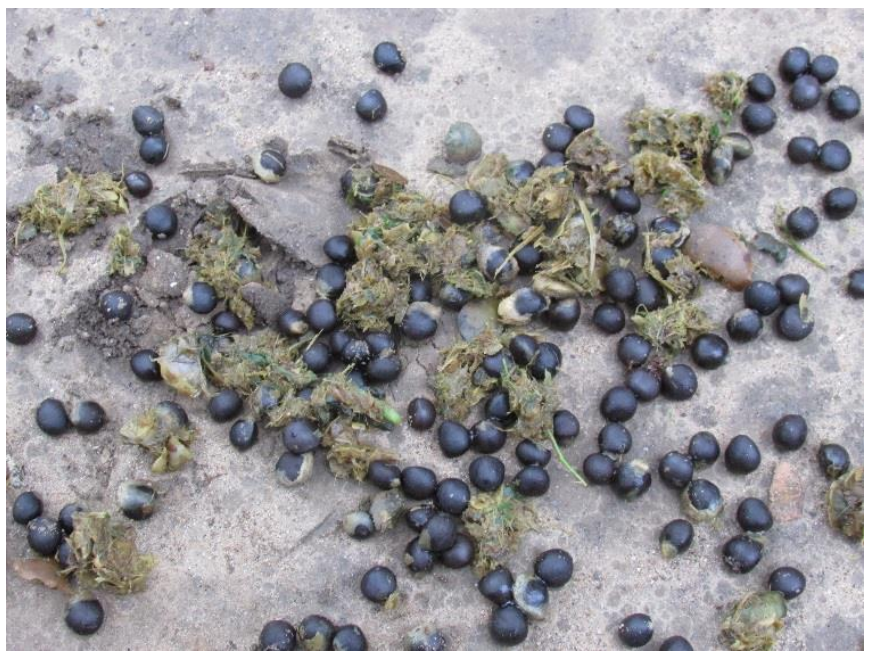

Figure 2. Trewia seeds (black) photographed at Gharial Conservation and Breeding Center, Kasara, Chitwan.

\section{2 | Count of seeds in fruits}

We also counted number of seeds in randomly collected 100 trewia fruits. The number of seeds within each fruit range between three and five with an average of 3.91 seeds (Fig. 2). Based on the seed count and number of seed groups, average number of fruits consumed by chitals per night was 169 in 2016 and 117 in 2017.

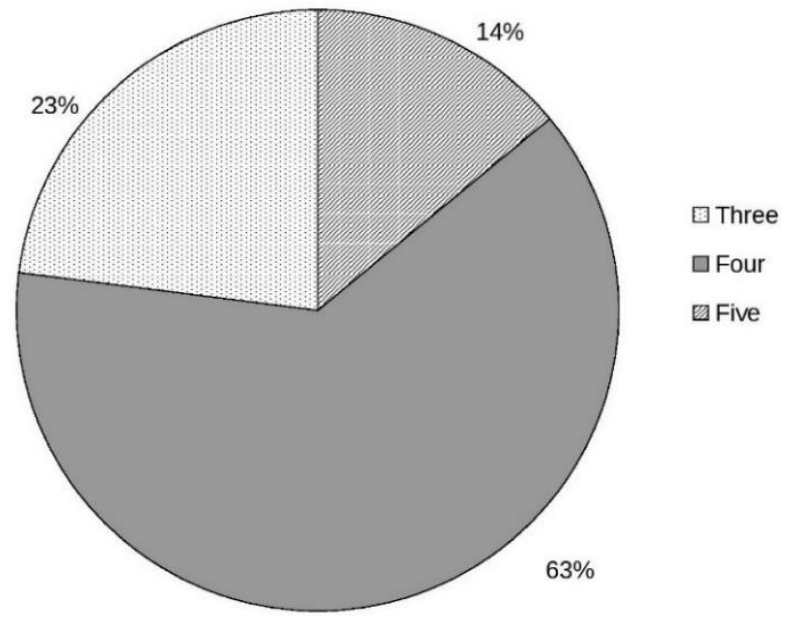

Figure 3. Number of seeds in trewia fruits.

Table 1. Frequency of groups and number of trewia seeds recorded in 2016 and 2017.

\begin{tabular}{|c|c|c|c|c|c|}
\hline 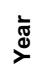 & Date & $\begin{array}{c}\text { No of seed } \\
\text { groups }\end{array}$ & $\begin{array}{c}\text { Average No } \\
\text { of seeds }\end{array}$ & $\begin{array}{c}\text { Range } \\
\text { (No of seeds) }\end{array}$ & $\begin{array}{l}\text { Standard } \\
\text { deviation }\end{array}$ \\
\hline \multirow{7}{*}{$\hat{\tilde{\delta}}$} & 18-Jul & 9 & 81 & 37 to 231 & 59.98 \\
\hline & 22-Jul & 7 & 168 & 32 to 343 & 120.71 \\
\hline & 24-Jul & 5 & 71 & 34 to 207 & 76.19 \\
\hline & 26-Jul & 7 & 88 & 37 to 181 & 55.44 \\
\hline & 30-Jul & 6 & 73 & 31 to 118 & 47.40 \\
\hline & 6-Aug & 7 & 102 & 36 to 196 & 63.70 \\
\hline & Average & 6.8 & 97 & $31-343$ & \\
\hline \multirow{16}{*}{$\stackrel{0}{\stackrel{N}{\circ}}$} & 6-Aug & 7 & 76 & 51 to 153 & 35.94 \\
\hline & 7-Aug & 2 & 138 & 69 to 69 & 96.87 \\
\hline & 9-Aug & 7 & 63 & 35 to 35 & 21.60 \\
\hline & 18-Aug & 7 & 83 & 42 to 0 & 49.11 \\
\hline & 22-Aug & 5 & 99 & 26 to 59 & 75.18 \\
\hline & 23-Aug & 6 & 108 & 33 to 33 & 27.90 \\
\hline & 24-Aug & 6 & 62 & 73 to 73 & 16.74 \\
\hline & 6-Sep & 8 & 72 & 32 to 32 & 44.44 \\
\hline & 7-Sep & 12 & 77 & 26 to 26 & 34.54 \\
\hline & 8-Sep & 6 & 60 & 29 to 29 & 17.87 \\
\hline & 11-Sep & 4 & 83 & 32 to 32 & 84.44 \\
\hline & 13-Sep & 3 & 81 & 24 to 36 & 35.55 \\
\hline & 22-Sep & 3 & 33 & 41 to 41 & 12.66 \\
\hline & 26-Sep & 6 & 61 & 19 to 38 & 17.20 \\
\hline & 29-Sep & 7 & 57 & 34 to 51 & 16.04 \\
\hline & Average & 5.9 & 77 & $19-153$ & \\
\hline
\end{tabular}




\section{4 | Discussion}

We documented the evidence of chital eating the trewia fruits and regurgitating the seeds in Chitwan National Park, Nepal. Chitals feed on grass, leaves and fruits that drop on the ground (Mishra 1982). In the riverine forests with trewia trees, their fruits are available at the forest floor which is easy food for the Chital during peak ripening period (June-August). Similarly, chitals, with their high abundance and widespread distribution in floodplains of Chitwan, may play an important role in seed dispersal of trewia by eating fruits and regurgitating out the seeds. Thus, mutually beneficial (commensal) relation between chital and trewia can be observed. However, their role in trewia seed dispersal is not understood well.

The undigested and freshly chewed parts of the fruits attached with trewia seeds suggests that chitals had regurgitated and thrown out the seeds, due to difficulty in chewing and swallowing. Similar observations of chital regurgitating Phyllanthus emblica seeds was observed in Rajaji National Park, India (Prasad et al. 2006). Chital is a ruminant species which regurgitate the swallowed food (cud) while foraging and chew the cud while resting. The trewia seed is too hard to chew, and too big ( $\sim \mathrm{mm})$ to swallow. Chitals probably throw the seeds and swallow the rest of the cud. Careful observation is required to distinguish the regurgitated trewia seeds as it resembles the chital pellet. Chitals gather in large numbers on open spaces as an anti-predatory strategy (Mishra 1982). Some seed groups were large (up to 343 seeds) probably a herd of chitals regurgitated it. Based on our measurement of the number of seeds within each fruit, $\sim 88$ fruits should have been consumed. Trewia fruits are often called 'rhino apple' but we suggest to call it also 'deer apple'.

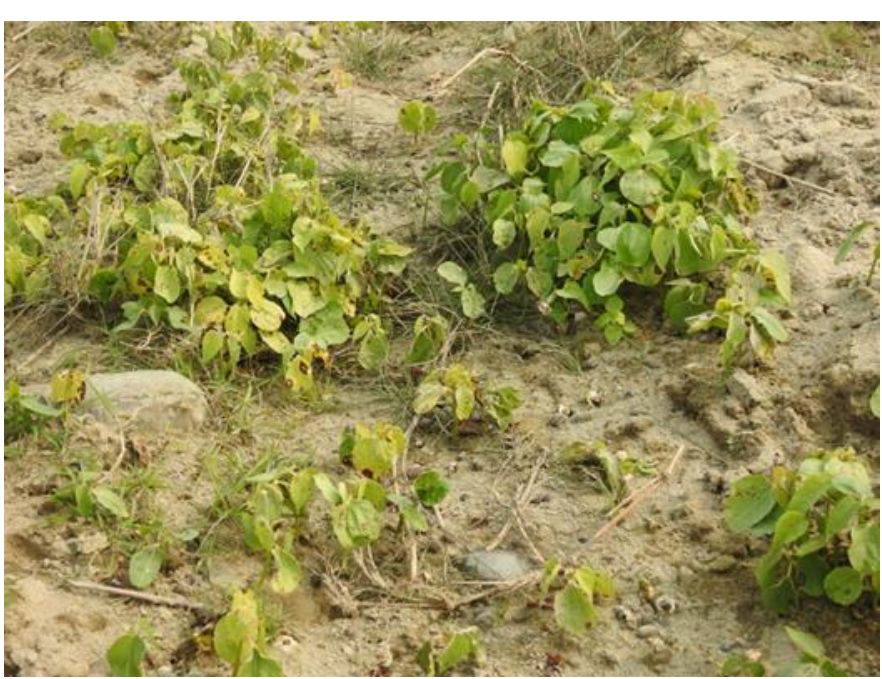

Figure 4. Regeneration of the trewia on the open space close to rivers where no traces of rhino dung detected, but plenty of Chital droppings. We assume that the seedlings grew from the seeds regurgitated by chitals.

This study has not tested the germination rate of the regurgitated seeds. However, germination of the seeds close to GCBC as well as riverbanks and open grassland areas i.e. chital's preferred resting sites, often away from the rhino dung areas, indicates good germination potential of the regurgitated seeds (Fig. 4). We suggest that chitals contributed in establishing the trewia forest in large portions of the River floodplains in Chitwan. We do not intend to undermine the role of rhinos in structuring the trewia forests (Dinerstein \& Wemmer 1988). But rhinoceroses have communal latrine and their droppings are confined to those latrine sites limiting the dispersal potential. The chital, in contrast, has widespread distribution and regurgitate in larger areas in open spaces of grasslands or river bank, where they rest. This increases the dispersal potentiality of trewia by the chitals.

\section{5 | Conclusions}

Role of chital in structuring the riverine habitats due to their high abundance may be greater than previously thought. Till now, rhinoceros is believed to be the primary agent for the trewia dispersal but we observed potentially a large role of chital. A detailed study on trewia-herbivore relationships particularly on Chital diet, quantification of trewia seed dispersal by chital, germination success of the regurgitated seeds is necessary to understand the trewia- chital relationship.

\section{Acknowledgements}

We thank Chitwan National Park and National Trust for Nature Conservation for their support in this study. We would like to thank also to staff of Gharial Conservation Breeding Center in Chitwan National Park, who helped in counting the seeds and cleaned the GCBC minimizing the chances of duplication of seeds.

\section{Authors' contributions}

Both authors designed the study; Khadka, B. B. conducted the fieldwork; both authors wrote the manuscript.

\section{Conflicts of interest}

Authors declare no conflict of interest. 


\section{ORCID}

Bed Bahadur Khadka (D) http://orcid.org/0000-0002-6382-8425

Babu Ram Lamichhane (D) https://orcid.org/0000-0003-0580-7682

\section{References}

Baral, H. S. 2001. Community structure and habitat associations of lowland grassland birds in Nepal. PhD Thesis, Universiteit of Amsterdam, Netherlands.

Bodemer, R. E. 1991. Strategies of seed dispersal and seed predation in Amazonian ungulates. Biotropica 23:255-261. https://doi.org/10.2307/2388202.

Cosyns, E., Delporte, A., Lens, L. and Hoffmann, M. 2005. Germination success of temperate grassland species after passage through ungulate and rabbit guts. Journal of Ecology 93:353-361. https://doi.org/10.1111/j.0022-0477.2005.00982.x.

Corlett, R. T. 1998. Frugivory and seed dispersal by vertebrates in the Oriental (Indomalayan) region. Biological Reviews 73:413-448. https://doi.org/10.1017/S0006323198005234.

Dhakal, M., Karki, M., Jnawali, S. R., Subedi, N., Pradhan, N. M. B., Malla, S., Lamichhane, B. R., Pokheral, C. P., Thapa, G. J., Oglethorpe, J., Subba, S. A. and Yadav, H. 2014. Status of tigers and prey in Nepal. Department of National Parks and Wildlife Conservation, Kathmandu, Nepal.

Dinerstein, E. 1989. The foliage-as-fruit hypothesis and the feeding behavior of South Asian ungulates. Biotropica 21:214-218. https://doi: 10.2307/2388646

Dinerstein, E. 1991. Seed dispersal by greater one-horned rhinoceros (Rhinoceros unicornis) and the flora of Rhinoceros latrines. Mammalia 55:355-362. https://doi.org/10.1515/mamm.1991.55.3 .355

Dinerstein, E. and Wemmer C. M. 1988. Fruits Rhinoceros eat dispersal of Trewia nudiflora (Euphorbiaceae) in lowland Nepal. Ecology 69:1768-1774. https://doi.org/10.2307/1941155.

Dubost, G. 1984. Comparison of the diets of frugivorous forest ruminants of Gabon. Journal of Mammalogy 65:298-316. https://doi.org/10.2307/1381169

Lamichhane, B. R., Leirs, H., Persoon, G. A., Subedi, N., Dhakal, M., Oli, B. N. et al. 2019. Factors associated with co-occurrence of large carnivores in a human-dominated landscape. Biodiversity and Conservation 28:1473-1491. https://doi: 10.1007/s10531-019-01737-4
Middleton, B. and Mason, D. H. 1992. Seed herbivory by Nilgai, Feral Cattle, and Wild Boar in the Keoladeo National Park, India. Biotropica 24:538-543. https://doi.org/10.2307/2389017

Mishra, H. R., 1982. The Ecology and Behaviour of Chital (Axis axis) in Royal Chitwan National Park, Nepal. PhD Thesis, University of Edinburgh, UK.

Prasad, S., Krishnaswamy, J., Chellam, R., Goyal, S. P. 2006. Ruminant-mediated Seed Dispersal of an Economically Valuable Tree in Indian Dry Forests. Biotropica 38:679-82. https://doi: 10.1111/j.1744-7429.2006.00182.x.

Subedi, N., Jnawali, S. R., Dhakal, M., Pradhan, N. M., Lamichhane, B. R., Malla, S., Amin R. and Jhala, Y. V. 2013. Population status, structure and distribution of the greater one-horned rhinoceros Rhinoceros unicornis in Nepal. Oryx 47:352-360.

\section{Cite this article as:}

Khadka, B. B. and Lamichhane B. R. 2020. Evidence of bhellar (Trewia nudiflora) seed dispersal by chital (Axis axis) in Chitwan National Park, Nepal. Nepalese Journal of Zoology 4(1):56-60. https://doi.org/10.3126/njz.v4i1.30674 